DOI: https://doi.org/10.47405/mjssh.v6i1.618

\begin{tabular}{|c|c|}
\hline 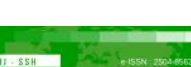 & Malaysian Journal of Social Sciences and Humanities (MJSSH) \\
\hline Malaysian Journal of & Volume 6, Issue 1, January 2021 \\
\hline (MJ-ssH) & e-ISSN : 2504-8562 \\
\hline & $\begin{array}{l}\text { Journal home page: } \\
\text { www.msocialsciences.com }\end{array}$ \\
\hline
\end{tabular}

\title{
Komitmen Organisasi Sekolah dan Hubungannya dengan Kualiti Pengajaran Guru Bahasa Melayu Tahap Satu di Luar Bandar Sabah
}

\author{
Latipah Binti Satangah @ Latifah Salim¹, Mohd Khairuddin Abdullah ${ }^{1}$ \\ ${ }^{1}$ Fakulti Psikologi dan Pendidikan, Universiti Malaysia Sabah (UMS) \\ Correspondence: Latipah Binti Satangah (latipah_mala@ymail.com)
}

\begin{abstract}
Abstrak
Kajian ini bertujuan untuk mengenal pasti tahap komitmen organisasi sekolah dan hubungannya dengan kualiti pengajaran guru dalam kalangan guru Bahasa Melayu tahap satu luar bandar. Pendekatan kuantitatif kaedah tinjauan menggunakan instrumen (soal selidik) bagi mengutip data ke atas 217 sampel dengan teknik persampelan kelompok dan rawak mudah. Instrumen terdiri daripada Organizational Commitment Measure (OCM) dan Kualiti Pengajaran Guru (PABest). Statistik deskriptif iaitu (min dan sisihan piawai) serta inferensi digunakan untuk menjawab persoalan kajian. Dapatan menunjukkan tahap Komitmen Organisasi Sekolah pada aras yang tinggi iaitu mencatatkan nilai skor min dan sisihan piawai $3.88(\mathrm{sp}=.28)$, dan Kualiti Pengajaran Guru turut memperoleh aras tinggi iaitu $4.15(\mathrm{sp}=.32)$. Hasil dapatan juga menunjukkan terdapat hubungan signifikan pada aras yang kuat antara komitmen $\left(r=.613^{* *}, \mathrm{p}=0.00\right)$ dengan kualiti pengajaran guru. Justeru itu, kajian ini menyimpulkan bahawa aspek komitmen organisasi sekolah guru merupakan salah satu indikator penting dalam memacu keberkesanan penyampaian ilmu pengetahuan seterusnya menyumbang terhadap kualiti pengajaran guru. Oleh itu, kajian ini mencadangkan agar komitmen organisasi sekolah dipertingkatkan dan dijadikan antara aspek keutamaan selari dengan aspek kualiti dalam perancangan pendidikan di negara ini bagi memastikan pencapaian membanggakan bukan sahaja dalam bidang akademik bahkan sahsiah secara menyeluruh.
\end{abstract}

Kata kunci: komitmen, organisasi, sekolah, kualiti, pengajaran

\section{School Organization Commitment and Its Relationship with the Quality of Level One Teachers Teaching Malay Language in the Rural Sabah area}

\begin{abstract}
The purpose of this study was identify the level of school organization commitment and its relationship to the quality of teaching among Malay Language teacher in rural area. The quantitative approach to the survey method uses instruments (questionnaires) to collect data on 217 samples with simple cluster and random sampling techniques. The instruments consist of Organizational Commitment Measure (OCM) and Teacher Teaching Quality (PABest). Descriptive statistics (mean and standard deviation) and inference were used to analysed the data. The findings show that the level of School Organization Commitment is at a high level, $\mathrm{m}=3.88(\mathrm{sp}=.28)$, and Teacher Teaching Quality also obtained a high level of $\mathrm{m}=4.15(\mathrm{sp}=.32)$. The findings also show that there is a significant relationship at a strong level between commitment $(\mathrm{r}=.613 * *, \mathrm{p}=0.00)$ with the quality of teacher teaching. Therefore, this study concludes that the commitment of teacher school organization is one of the important indicators in driving the effectiveness of knowledge delivery and in turn contribute to the quality of teacher
\end{abstract}


teaching. Therefore, this study suggests that the commitment of school organization is enhanced and given the same priority with the quality aspects in educational planning in this country to ensure a proud achievement not only in the academic field but also personality as a whole.

Keywords: commitment, organizational, school, quality, teaching

\section{Pengenalan}

Mengimbau zaman sebelum peradaban, Bahasa Melayu yang dikenali sebagai Bahasa Purba, kini telah menunjukkan potensinya melalui transformasi yang berlaku ke atas bahasa ini sebagai salah satu bahasa Moden dengan keupayaannya memiliki penutur keempat terbanyak di peringkat dunia (Pelan Hala Tuju Pendidikan Bahasa Melayu: 2016-2025) (Kementerian Pendidikan Malaysia, 2017). Melalui pembuktian tersebut, menunjukkan bahawa potensi tinggi Bahasa Melayu berupaya melakar sejarah sebagai salah satu bahasa komunikasi utama dipertuturkan di peringkat antarabangsa (KPM, 2017). Justeru itu, selaku rakyat di Nusantara Melayu dan sebagai penutur jati bahasa ini amat wajar rasa bangga terhadap potensi Bahasa Melayu meletakkan diri di persada antarabangsa. Namun, penggunaan dan penguasaan Bahasa Melayu sebagai bahasa kebangsaan masih kurang memuaskan di negara ini (KPM, 2017), berdasarkan pada pencapaian prestasi khususnya murid sekolah rendah (KPM, 2017). Hal ini terhubung dengan hasil verifikasi kendiri Pembelajaran dan Pemudahcaraan Guru (PdPc) Berdasarkan Standard 4, SKPMg2, Jemaah Nazir dan Jaminan Kualiti (JNJK) (KPM, 2018), yang menunjukkan bahawa hanya $26 \%$ mencapai tahap cemerlang dalam PdPc, manakala sebahagian besar iaitu 74\% sekadar mencapai tahap baik iaitu paling minimum.

Komitmen merupakan antara faktor berpengaruh terhadap tinggi rendahnya prestasi kerja seseorang guru. Hal ini terkait kerana tingkah laku komitmen guru menyumbang terhadap pencapaian akademik murid dan prestasi sekolah (Mohamad, Zakaria \& Nasir, 2017), Thien, Razak dan Ramayah (2014) serta (Shafikani, 2016). Tanpa adanya komitmen tinggi, tanggungjawab dan standard diri yang lemah akan menjejaskan matlamat pendidikan. Jelasnya, tingkah laku komitmen menyumbang ke atas komponen kualiti dalam pendidikan. Justeru itu, komitmen dalam kalangan guru adalah amat penting dalam memacu kualiti pengajarannya seterusnya pencapaian prestasi kemenjadian murid meliputi aspek rohani dan jasmani selari dengan kehendak FPN. Diperkukuhkan dalam kajian Webrecruit (2015) bahawa komitmen guru ke atas tugasnya memperlihatkan prestasi kerja yang lebih berkualiti melebihi daripada apa yang diarahkan.

Menyedari hakikat tersebut, gerakan transformasi sistem pendidikan di negara ini adalah bertepatan dan bersesuaian dengan matlamat dan usaha meletakkan kualiti sebagai wasilah keutamaan menyeluruh dalam Pelan Pembangunan Pendidikan Malaysia (PPPM) 2013-2025 (KPM, 2013). Keutamaan ke atas aspek kualiti pengajaran guru dalam memacu pemerolehan kemenjadian murid amat jelas sebagai hala tuju melalui penetapan objektif memartabatkan sistem pendidikan negara yang berkualiti setaraf dengan antarabangsa.

Literatur terdahulu masih kurang mengkaji pemboleh ubah komitmen organisasi sekolah dan kualiti pengajaran guru, khususnya di luar bandar (Billy \& Muhamad Suhaimi Taat, 2020; Hanaysha, 2016). Justeru itu, kajian ini dilaksanakan bagi gambaran berdasarkan matlamat dan objektif sekaligus sebagai nilai tambah ke atas dapatan terdahulu dalam menggambarkan aspek yang dikaji ke arah memantapkan kualiti pendidikan di negara ini.

\section{Sorotan Literatur}

Blandford (2010), merujuk kualiti adalah apa-apa yang disebut sebagai elemen atau aspek organisasi yang mengarah kepada pencapaian objektif suatu tahap prestasi yang diinginkan oleh pelanggan. Pemakaian kualiti diperluaskan ke bidang lain seperti pendidikan sebagai kejayaan sesebuah sekolah mewujudkan persekitaran pendidikan yang membolehkan pelajar mencapai matlamat pembelajaran 
serta piawaian akademik yang sewajarnya secara berkesan melalui kualiti pengajaran guru (Standard Kualiti Pendidikan Malaysia [SKPM], KPM, 2010). Fullan (2009), mentakrifkan kualiti pengajaran guru sebagai ilmu perguruan yang diperoleh melalui kursus asas dan lanjutan dalam perkhidmatan. Selari dengan LeTendre dan Wiseman (2015), bahawa kualiti pengajaran iaitu keupayaan guru menghubungkan tiga aspek iaitu pengetahuan akademik yang dimiliki dengan ciri guru serta keadaan kerja bagi menghasilkan kualiti dalam pengajaran.

Diperjelaskan oleh Batjo dan Ambotang (2019) bahawa pengajaran guru mempengaruhi kualiti pengajarannya melalui pengkaedahan. Selain itu, tingkah laku pengurusan bilik darjah guru yang berkesan, kawalan disiplin dan menyerlahkan keterampilan diri sebagai guru berkesan, jelas berkaitan dengan keupayaan guru untuk menetapkan nada yang sesuai dan mendapat penghormatan dan kerjasama pelajar di kelas (Williams \& Burden, 1997; Rahimi \& Karkami, 2015). Justeru itu, Blase dan Blase (1999), Dewi (2015) dan Haslina et al. (2017) merumuskan bahawa kejayaan sesebuah sekolah adalah disebabkan oleh kualiti pengajaran guru. KPM (2013) menjelaskan bahawa kualiti sistem tidak boleh melangkaui kualiti guru. Ini bermakna, betapa pentingnya peranan kualiti guru dalam pengajarannya untuk memacu prestasi pencapaian murid.

Komitmen merupakan sikap kesungguhan seseorang pekerja ke atas pekerjaannya yang penting untuk dilakukan agar pelaksanaan dan hasil kerja lebih baik dicapai. Menurut Ahmad Shukri (2002) dan Luthans (2002) komitmen ialah satu sikap di tempat kerja yang penting kepada pengurusan sesebuah organisasi. Antara kajian komitmen dalam konteks pendidikan adalah seperti kajian oleh Xiao \& Wilkins (2015) yang meneliti komitmen organisasi dalam kalangan pensyarah. Manakala Talip dan Tiop (2020), Md Yasin dan Mohd Hamzah (2018) dan Ling et al. (2013) pula menjalankan kajian mengenai hubungan kepimpinan pentadbir dengan komitmen kerja guru serta kajian-kajian lain yang berkaitan (Thien, Razak \& Ramayah, 2014; Yusof \& Wahab, 2019; Sankaran, 2017; Shafiq \& Rana, 2016),

\section{Objektif kajian}

Objektif kajian adalah seperti berikut:

i. Mengenal pasti tahap komitmen organisasi sekolah dan kualiti pengajaran guru Bahasa Melayu tahap satu.

ii. Mengenal pasti sama ada terdapat hubungan antara komitmen organisasi sekolah dengan kualiti pengajaran guru Bahasa Melayu tahap satu.

\section{Metod Kajian}

Kaedah tinjauan digunakan untuk mengutip data melalui borang soal selidik yang diedarkan kepada responden. Seramai 217 orang guru Bahasa Melayu tahap satu kawasan luar bandar Sabah di keempatempat PPD iaitu PPD Tambunan, Keningau, Tenom dan Nabawan/Pensiangan yang diplih menggunakan teknik persampelan kelompok dan rawak mudah. Instrumen komitmen organisasi sekolah menggunakan "A Psychometric Assessment Of The Malay Version Of Meyer And Allen's Organizational Commitment Measure' (OCM) oleh Allen dan Mayer's (1990). Terjemahan Back To Back telah dilakukan oleh pakar dalam kedua-dua bahasa agar maksud konsisten dengan terjemahan pengkaji terdahulu. Manakala instrumen Kualiti Pengajaran Guru (PABest-Penilaian Anugerah Beluran, Sandakan dan Telupid), oleh Hor, C. W. (2012) turut digunakan. Alat statistic SPSS diaplikasi bagi menganalisis data deskriptif dan inferensi. 


\section{Dapatan dan Perbincangan}

\section{Demografi Responden (Jantina dan Pengalaman Mengajar)}

Jadual 1 menunjukkan taburan responden mengikut jantina dan pengalaman mengajar. Didapati bahawa bilangan responden mengikut jantina adalah 27.6 peratus guru lelaki iaitu seramai 60 orang. Manakala 72.4 peratus guru perempuan iaitu seramai 157 orang yang terlibat kajian ini. Dominasi bilangan guru wanita yang ramai ini tidak dapat dielakkan dalam pemilihan kaedah pensampelan rawak dalam populasi kajian yang mempunyai responden guru perempuan lebih ramai daripada guru lelaki. Manakala bagi aspek pengalaman mengajar, didapati bahawa bilangan responden mengikut pengalaman mengajar adalah 22.1 peratus guru berpengalaman mengajar kurang daripada 6 tahun iaitu seramai 48 orang. Manakala, terdapat 25.3 peratus guru berpengalaman mengajar selama 7 hingga 12 tahun iaitu seramai 55 orang dan seramai 18.9 peratus orang guru iaitu 41 orang yang berpengalaman mengajar selama 13 hingga 18 tahun. Selain itu, terdapat 20.3 peratus atau 44 orang guru yang berpengalaman mengajar selama 19 hingga 24 tahun dan seramai 13.4 peratus iaitu 29 orang guru yang berpengalaman mengajar selama 25 tahun ke atas sebagai responden kajian.

Jadual 1: Taburan Responden Mengikut jantina dan Pengalaman Mengajar

\begin{tabular}{lccccccc}
\hline & \multicolumn{7}{c}{ Pengalaman Mengajar } \\
\cline { 2 - 7 } $\begin{array}{l}\text { Responden } \\
\text { (Guru BM }\end{array}$ & $\begin{array}{c}\text { 6 tahun ke } \\
\text { Tahap Satu) }\end{array}$ & $\begin{array}{l}\text { 7 hingga 12 } \\
\text { baw hingga 18 } \\
\text { tahun }\end{array}$ & $\begin{array}{l}\text { 19 hingga 24 } \\
\text { tahun }\end{array}$ & $\begin{array}{l}\text { 25 tahun ke } \\
\text { tahun }\end{array}$ & Jumlah \\
\hline Lelaki & 14 & 19 & 10 & 11 & 6 & 60 \\
& $6.5 \%$ & $8.8 \%$ & $4.6 \%$ & $5.1 \%$ & $2.8 \%$ & $27.6 \%$ \\
Perempuan & 34 & 36 & 31 & 33 & 23 & 157 \\
& $15.7 \%$ & $16.6 \%$ & $14.3 \%$ & $15.2 \%$ & $10.6 \%$ & $72.4 \%$ \\
Jumlah & 48 & 55 & 41 & 44 & 29 & 217 \\
& $22.1 \%$ & $25.3 \%$ & $18.9 \%$ & $20.3 \%$ & $13.4 \%$ & $100.0 \%$ \\
\hline
\end{tabular}

\section{Tahap Komitmen Organisasi Sekolah dan Kualiti Pengajaran Guru Bahasa Melayu Tahap Satu}

Jadual 2 menunjukkan dapatan skor min bagi dimensi komitmen organisasi sekolah dan kualiti pengajaran guru. Instrumen komitmen organisasi sekolah terdiri daripada tiga dimensi iaitu afektif, berterusan dan normatif. Manakala kualiti pengajaran guru terdiri daripada empat dimensi iaitu kenal diri, kesungguhan, inovatif dan kaedah pengajaran.

Jadual 2 : Skor Min Komitmen organisasi Sekolah dan Kualiti Pengajaran

\begin{tabular}{ccccc}
\hline Pemboleh ubah & Dimensi & Min & SP & Interpretasi \\
\hline Komitmen Organisasi & Afektif & 4.05 & .45 & Tinggi \\
& Berterusan & 3.84 & .40 & Tinggi \\
& Normatif & 3.76 & .21 & Tinggi \\
\hline Kualiti Pengajaran & Kenal diri & 4.27 & .39 & Sangat tinggi \\
& Kesungguhan & 4.18 & .43 & Tinggi \\
& Kaedah pengajaran & 4.13 & .25 & Tinggi \\
& Inovatif & 4.04 & .39 & Tinggi \\
\hline
\end{tabular}

Berdasarkan Jadual 2, secara keseluruhannya, ditunjukkan nilai min bagi tahap setiap dimensi komitmen organisasi sekolah. Bagi dimensi afektif, mempunyai tahap lebih tinggi iaitu $(\min =4.05$, $\mathrm{sp}=.45)$. Diikuti oleh dimensi berterusan kedua tertinggi iaitu $(\min =3.84, \mathrm{sp}=.40)$ dan dimensi normatif turut memperoleh skor min tinggi iaitu $(\min =3.76, \mathrm{sp}=.21$, sebagai dimensi yang ketiga. Komitmen Afektif menunjukkan tahap tertinggi di antara ketiga-tiga dimensi. Hal ini bermakna guru Bahasa Melayu tahap satu luar bandar rasa gembira dan seronok seterusnya bersungguh-sungguh 
mengajar di sekolah semasa. Ini didorong dengan wujudnya perasaan bahawa merasakan sekolah mempunyai makna ke atas diri.

Komitmen berterusan memperoleh tahap kedua tertinggi. Ini menunjukkan guru-guru lebih cenderung tetap kekal di sekolah semasa bagi suatu tempoh yang lama. Atas dasar pertimbangan bahawa bimbang tidak memperoleh manfaat yang sama di sekolah baharu. Akhir sekali aspek komitmen normatif yang menghubungkan kesungguhan guru ke atas sekolah berdasarkan suatu kewajaran norma yang patut dipatuhi dan kewajipan moral yang dijelaskan bahawa jika kerap berpindah sekolah seolah tiada etika.

Demikian juga turut memperoleh dapatan tahap tinggi ke atas semua dimensi pemboleh ubah kualiti pengajaran guru. Dimensi kenal diri mempunyai tahap skor min sangat tinggi iaitu $(\min =4.27, \mathrm{sp}=.39)$. Diikuti dimensi kesungguhan, yang mempunyai tahap skor min tinggi iaitu ( $\min =4.19, \mathrm{sp}=.43$ ). Seterusnya dimensi kaedah pengajaran dan inovatif juga mempunyai tahap min tinggi iaitu masingmasing mencatat $(\min =4.14, \mathrm{sp}=.25)$ dan $(\min =4.05, \mathrm{sp}=.39)$.

Berdasarkan dapatan, aspek kenal diri guru menunjukkan dapatan tahap sangat tinggi. Ini menunjukkan aspek kendiri guru mengenali kekuatan dan kemampuan diri dalam pelaksanaan proses PdPc. Guru berpengetahuan dan ada kefahaman mendalam tentang subjek Bahasa Melayu, dapat mengawal disiplin, mengurus kelas dengan baik dalam kalangan guru subjek Bahasa Melayu tahap satu melalui proses PdPc. Keadaan ini merujuk pada efikasi pengajaran yang tinggi guru bahawa pelaksanaan PdPcnya mampu berjaya dan berkesan.

Kesungguhan adalah aspek kedua tertinggi iaitu hal ini menunjukkan komitmen tinggi guru dalam melaksanakan tugas mengajar di sekolah, kelas tambahan, pelbagai program peningkatan, dan tugastugas khas lain atas dasar didorong oleh matlamat diri yang ingin memacu peningkatan prestasi sekolah secara umum khususnya prestasi pencapaian murid. Kaedah pengajaran merujuk pada pemilihan teknik dan aktiviti guru yang bersesuaian dengan isi kandungan iaitu proses PdPc bermula daripada konsep yang mudah beransur kepada yang kompleks. Komunikasi yang mudah difahami, termasuk pemilihan Bahan Bantu Mengajar yang berasaskan teknologi seperti ICT dalam PdPc.

Inovatif merujuk pada amalan proaktif guru menggunakan kaedah terkini dalam penyampaian PdPc seperti penerapan kemahiran berfikir, teknik penyoalan yang beransur dan sistematik berdasarkan Taksonomi Bloom, mengaitkan isi pelajaran dengan kehidupan harian murid dan sentiasa berinisiatif mencari kaedah yang berkesan untuk membantu pengajaran dalam kelas.

\section{Hubungan Komitmen Organisasi Sekolah dengan Kualiti Pengajaran Guru}

Jadual 3 menunjukkan terdapat hubungan linear positif yang kuat antara komitmen organisasi sekolah dengan kualiti pengajaran guru. Dapatan kajian menunjukkan terdapat hubungan yang signifikan ( $r$ $\left.=.613^{* *}, \mathrm{p}<0.05\right)$ antara komitmen organisasi dengan kualiti pengajaran guru, iaitu semakin tinggi tahap komitmen organisasi, maka semakin tinggi tahap kualiti pengajaran guru. Jelasnya, hubungan ini adalah hubungan linear positif yang kuat dan hubungan adalah signifikan. Ini bermakna, komitmen organisasi sekolah mendatangkan impak yang kuat terhadap kualiti pengajaran guru.

Jadual 3 : Hubungan Komitmen Organisasi Dengan Kualiti Pengajaran Guru

\begin{tabular}{lll}
\hline & Nilai Korelasi & Kualiti Pengajaran Guru \\
\hline Komitmen Organisasi & $r$ & $.613^{* *}$ \\
Sekolah & Sig. & .000 \\
& $\mathrm{~N}$ & 217 \\
\hline
\end{tabular}




\section{Implikasi}

Dapatan kajian ini dapat mengukuhkan dan mengesahkan kefahaman terhadap penyataan kedua-dua model yang mendasari kajian ini sebagai sokongan dalam menerangkan aspek yang dikaji, iaitu Model Komitmen Allen dan Mayer (1990) yang terdiri daripada tiga dimensi keterikatan terhadap keinginan kekal dalam organisasi iaitu berkaitan dengan afektif, berterusan dan normatif dan Model SKPMg2 Standard Empat, iaitu berkenaan dengan pengajaran dan pemudahcaraan guru dalam PdPc.

Seiring dengan usaha peningkatan kemahiran profesionalisme berterusan dalam kerjaya sebagai seorang guru dan bagi memastikan pelaksanaan tugas sebagai pendidik benar-benar berkesan atau berkualiti, maka perlunya ada komitmen yang tinggi ke atas tanggungjawab selaku pemudah cara pembelajaran murid dalam bilik darjah. Komitmen ke atas organisasi sekolah merupakan pelengkap bagi pelaksanaan tugas guru dan merupakan elemen ke arah penghasilan kerja yang berkualiti. Sekadar wujudnya kecekapan dan kemahiran dalam diri guru, belum memadai penyempurnaan tugas dilakukan melainkan dengan adanya komitmen yang tinggi sebagai penyudahnya. Hal ini bermakna, dengan menetapkan kualiti sebagai keutamaan hala tuju pendidikan di negara ini, justeru perlu meletakkan aspek lain secara seiringan seperti komitmen dalam rangka pelan pembangunan pendidikan sebagai keutamaan sama penting dengan kualiti agar matlamat kualiti dapat dicapai melalui pemerkasaan ke atas aspek komitmen guru.

Demikian juga warga pendidik perlu menanamkan nilai kesungguhan diri yang realistik selaras dengan nilai sekolah dengan menterjemahkannya dalam bentuk komitmen tinggi terhadap pelaksanaan kerja agar dapat mencapai matlamat berkualiti seperti yang diharapkan. Kajian seumpama ini perlu diperluaskan bagi melihat aspek lain yang berkaitan dengan penghasilan kualiti pengajaran guru agar usaha ke arah pendidikan berkualiti di negara ini tidaklah sia-sia belaka, justeru matlamat kerajaan khususnya KPM wajar dijunjung dan direalisasikan oleh semua elemen dan komponen dalam pendidikan.

\section{Kesimpulan}

Tidak dapat dinafikan bahawa komitmen guru terhadap organisasi sekolah secara umumnya memberi impak ke atas penghasilan kualiti dalam sistem pendidikan. Hal ini dapat diperlihatkan melalui sikap dan kesungguhan melaksanakan tugas yang dipertanggungjawabkan menggambarkan cerminan ke atas persembahan kerja yang lebih berkesan dan berkualiti. Justeru itu mengekal dan meningkatkan tahap komitmen ke atas sekolah amat perlu dalam kalangan warga pendidik dan umumnya semua dimensi dalam sistem pendidikan bagi menjamin pencapaian matlamat kualiti pendidikan di negara ini.

\section{Rujukan}

Abdullah, M. K., \& Laji, H. (2016). Analisis Perbandingan Efikasi Pengajaran Dan Kalangan Guru Bahasa Melayu Tahun Satu (A Comparison Of The Teaching Efficacy Among Primary One Malay Language Teachers). Jurnal Pendidikan Bahasa Melayu, 5(1), 10-17.

Ahmad, N. L., \& Azman, N. A. H. (2020). Tahap Amalan Pengajaran Berkesan Guru Prinsip Perakaunan Berasaskan Model Slavin. Malaysian Journal of Education, 45(1).

Ahmad Shukri Mohd Nain. 2002. Tingkahlaku Organisasi. Johor: UTM

Ali, S. B., \& Yunus, J. N. B. H. (2017). Pengaruh Gaya Kepemimpinan Situasi Guru Besar terhadap Komitmen Kerja Guru di Bintulu Sarawak. Tarbawi: Jurnal Keilmuan Manajemen Pendidikan, 1(01), 119-132.

Allen, N. J., \& Meyer, J. P. (1990). The measurement and antecedents of affective, continuance and normative commitment to the organization. Journal of Occupational Psychology, 63(1), 1- 18.

Asghar Hayat, A. (2018). The role of irrational beliefs in predicting teacher's organizational commitment. International Journal of Occupational Hygiene, 10(4). 
Baco, B., Arifin, K., \& Awang, A. (2020). Komitmen dalam Pengurusan Kualiti di Sekolah: Konsep dan Kerelevanannya (Commitment on School Quality Management: Concept and Relevance). Akademika, 90(3).

Baharuddin, J., Mohammad Saad, N., \& Ismail, S. N. (2017). Pengurusan krisis di sekolah dan hubungannya dengan komitmen guru sekolah menengah di Negeri Kelantan. Proceeding of ICECRS, 1, 187-198.

Baliyan, S. P., \& Moorad, F. R. (2018). Teaching Effectiveness in Private Higher Education Institutions in Botswana: Analysis of Students' Perceptions. International Journal of Higher Education, 7(3), 143-155.

Batjo, N., \& Ambotang, A. S. (2019). Pengaruh Pengajaran Guru Terhadap Kualiti Pengajaran Guru. Malaysian Journal of Social Sciences and Humanities (MJSSH), 4(2), 30-42.

Biermann, A., Karbach, J., Spinath, F. M. \& Brünken, R. (2015). Investigating effects of the quality of field experiences and personality on perceived teaching skills in German pre-service teachers for secondary schools.Teaching and Teacher Education, 51,7787.http://doi.org/10.1016/j.tate.2015.06.005.

Billy, L. J., \& Taat, M. S. (2020). Budaya Sekolah: Hubungannya dengan Komitmen Guru. Malaysian Journal of Social Sciences and Humanities (MJSSH), 5(10), 207-216.

Blase, J., \& Blase, J. (1999). Principals' instructional leadership and teacher development: Teachers' perspectives. Educational administration quarterly, 35(3), 349-378.

Blandford, S. (2010). Mengurus Pembangunan Profesional di Sekolah. Institut Terjemahan Negara Malaysia. Kuala Lumpur.

Chowdhury, F. (2019). "Blended learning: how to flip the classroom at HEIs in Bangladesh?", Journal of Research in Innovative Teaching \& Learning, 13(2), 228-242. https://doi.org/10.1108/JRIT-122018-0030.

Cooper, J. M. (Ed.). (1977). Classroom teaching skills: a handbook. Lexington Books.

Cruz, F. J. F., \& Díaz, M. J. F. (2016). Generation z's teachers and their digital skills. Comunicar.Media Education Research Journal, 24(1).

Dewi Isma Madzlan. (2015). Program Pembangunan Profesionalisme Guru, Faktor Stress Kerja Terhadap Efikasi Guru-guru Sekolah Menengah Di Sabah. Unpublished doctoral dissertation, Universiti Malaysia Sabah.

Ebbie, S. B., Talip, R. B., \& Kiflee, D. N. A. (2019). Pengaruh Kepimpinan Pengajaran Guru Besar, Kompetensi Profesionalisme Guru dan Kompetensi Peribadi Guru Terhadap Efikasi Pengajaran Guru Sekolah Rendah di Zon Pedalaman Sabah. Malaysian Journal of Social Sciences and Humanities (MJSSH), 4(8), 29-38.

Feng, L, \& Sass, T. (2014). Teacher Quality and Teacher Mobility. National Center for Analysis of Longitudinal Data in Education Research Working Paper, 57: 1-30.

Fullan, M. (Ed.). (2009). The challenge of change: Start school improvement now!. Corwin Press.

Haslina Hamzah, Noor Shamshinar Zakaria, Mohd Izzuddin Mohd Pisol, Julia Madzalan \& Syed Mohd Najib Syed Yahya.(2017). Persepsi Guru Bukan Opsyen Tentang Pengajaran Bahasa Arab: Satu Kajian Terhadap Guru Pendidikan Islam Di Beberapa Sekolah Rendah Agama Jais Daerah Hulu Langat Selangor. E-Jurnal Penyelidikan Dan Inovasi Rmc.Kuis.Edu.My/Jpi/ E-ISSN 22897909.

Hanaysha, J. (2016). Examining the Effects of Employee Empowerment, Teamwork, and Employee Training on Organizational Commitment. Procedia-Social and Behavioral Sciences, 229, 298306.

Hor, C. W. (2012). Pengaruh kepimpinan pengajaran pengetua dan kualiti pengajaran guru terhadap pembelajaran pelajar di sekolah (Doctoral dissertation, Universiti Malaysia Sabah).

Hushaini, N. H., Osman, Z., \& Sarudin, A. (2020). Pelaksanaan Amalan Terbaik Pengajaran Bahasa Melayu Dalam Kalangan Guru Sekolah Rendah (The Implementation Of Best Teaching Practices Of Malay Language Among Primary School Teachers). Jurnal Pendidikan Bahasa Melayu, 10(1), 1-13.

Ismail, S. N., Abdullah, Z., Othman, A. J., \& Shafie, S. (2018). Amalan Komuniti Pembelajaran profesional dalam kalangan guru Bahasa Melayu di Selangor. JuPiDi: Jurnal Kepimpinan Pendidikan, 5(4), 1-19.

Jamail, M., \& Don, Y. (2017). Praktis kepimpinan distributif dan komitmen terhadap organisasi berdasarkan kohort generasi guru. Proceedings of the ICECRS, 1(1), 275-286. 
Jamian, A. R. 2016. Permasalahan kemahiran membaca dan menulis Bahasa Melayu murid- murid sekolah rendah di luar bandar. Jurnal Pendidikan Bahasa Melayu, 1(1), 1-12.

Janary Anak Lumbai. (2016). Pengaruh amalan kepimpinan berstruktur, efikasi guru dan norma-norma budaya terhadap keprihatian tugas guru sekolah kebangsaan di Sarawak. Thesis. Unversiti Malaysia Sabah.

Jo, S. H. (2014). Teacher commitment: Exploring associations with relationships and emotions. Teaching and Teacher Education, 43: 120-130.

Kementerian Pendidikan Malaysia. 2016. Dokumen Awal Pelan Induk Pembangunan Profesionalisme Keguruan. BPG. KPM. Putrajaya, Kuala Lumpur.

Kementerian Pendidikan Malaysia. (2013). Pelan Pembangunan Pendidikan Malaysia (PPPM) 20132025. Laporan Awal \& Ringkasan Eksekutif. KPM. Putrajaya, Kuala Lumpur.

Kementerian Pendidikan Malaysia. (2017). Pelan Hala Tuju Pendidikan Bahasa Melayu 2016- 2025. 2017. Bahagian Perancangan dan Penyelidikan Dasar Pendidikan.

Kementerian Pendidikan Malaysia. (2017). Standard Kualiti Pendidikan Malaysia Gelombang 2 (SKPMg2). Jemaah Nazir dan Jaminan Kualiti. Percetakan Pro Dinasti Sdn. Bhd. Putrajaya. Kuala Lumpur.

Krejcie, R. V., \& Morgan, D. (1970). Determining Sample Size for Research Activities. Educational and Psychological Measurement, 30, 607-610.

Kyriakides, L. C. R. J., Campbell, R. J., \& Gagatsis, A. (2000). The significance of the classroom effect in primary schools: An application of Creemers' comprehensive model of educational effectiveness. School effectiveness and school improvement, 11(4), 501-529.

Kyriakides, L., Creemers, B. P., \& Antoniou, P. (2009). Teacher behaviour and student outcomes: Suggestions for research on teacher training and professional development. Teaching and teacher education, 25(1), 12-23.

Ling, S., Ling, M., Sani, M., \& Ibrahim, B. (2013). Transformational Leadership and Teacher Commitment in Secondary Schools of Sarawak. International Journal of Independent Research and Studies, 2(2): 51-65.

Luthans, Fred. (2002). Organizational Behavior. ninth Edition. McGraw-Hill. Inc., New York.

Lumbai, J., \& Zain, S. (2016). Pengaruh Amalan Kepimpinan Berstruktur, Efikasi Guru dan NormaNorma Budaya Terhadap Keprihatinan Guru Sekolah Kebangsaan di Sarawak. Malaysian Journal of Social Sciences and Humanities (MJSSH), 1(3), 152-183.

Marzuki, S. (1998). Pengajaran Guru yang Berkesan Berdasarkan Model Slavin: Satu kajian di Sekolah Rendah Berkesan di Malaysia. Bangi: Tesis Ijazah Doktor Falsafah di fakulti Pendidikan Universiti Kebangsaan Malaysia.

Mazlan, R. (2017). Tahap Pengetahuan, Pemahaman Dan Kesediaan Guru Bahasa Melayu Dalam Melaksanakan Kajian Pengajaran (Level Of Knowledge, Understanding And Readiness Malay Language Teachers To Implementing Lesson Study). Jurnal Pendidikan Bahasa Melayu, 7(2), $30-40$.

Mazlan, R., \& Mahamod, Z. (2016). Faktor-Faktor Yang Mempengaruhi Kesediaan Guru Bahasa Melayu Melaksanakan Kajian Pengajaran. Malaysian Journal of Education (0126-6020), 41(2).

Meyer, J.P. and Allen, N.J., (1991). A three component conceptualisation of organisational commitment". Human Resource Management Review, 1, 1, 61-89.

Md Yasin, Z., \& Mohd Hamzah, M. I. (2018). Amalan kepimpinan instruksional pengetuadan hubungannya dengan komitmen guru di sekolah menengah daerah Seremban, Negeri Sembilan. Jurnal Pengurusan dan Kepimpinan Pendidikan, 31(1).

Mohamad, F., \& Ismail, S. N.( 2018). Kepimpinan Strategik Dan Hubungannya Dengan Kualiti Pengajaran Guru. JuPiDi: Jurnal Kepimpinan Pendidikan, 5(2), 14-25.

Mohamad, R., Zakaria, S., \& Nasir, F. M. (2017). Komitmen guru dan kepuasan $\quad$ kerja guru disekolah menengah harian berprestasi tinggi dan berprestasi rendah di Daerah Kota Bharu, Kelantan. Proceedings of the ICECRS, 1(1).

Rahimi, M., \& Karkami, F. H. (2015). The Role of Teachers' Classroom Discipline in Their Teaching Effectiveness and Students' Language Learning Motivation and Achievement: A Path Method. Iranian Journal of Language Teaching Research, 3(1), 57-82.

Raja Ismail, R. A., \& Ismail, D. (2018). Aplikasi 'Konsep 4c' Pembelajaran Abad Ke-21 Dalam Kalangan Guru Pelatih Pengajian Agama Institut Pendidikan Guru Kampus.

Ramakrishnan, K., \& Abd Hamid, A. H. (2020). Kepimpinan Strategik Dan Hubungannya Dengan 


\section{DOI: https://doi.org/10.47405/mjssh.v6i1.618}

Kualiti Pengajaran Guru Di Sekolah Kluster Tamil Daerah Pasir Gudang. Jurnal Dunia Pendidikan, 2(2), 57-64.

Safikhani, R. (2016). The Relation between Morality and Organizational Commitment of the Teachers with the Training Quality Level of Students in the City of Tehran Girls' Secondary Schools. The International Journal of Indian Psychology, 3(4).

Sowell, J. (2017). Good Instruction-Giving in the Second-Language Classroom. In English Teaching Forum, 55(3), 10-19.

Thien, L. M., Razak, N. a., \& Ramayah, T. (2014). Validating Teacher Commitment Scale Using a Malaysian Sample. SAGE Open, 4(2): 1-9.

Webrecruit Ireland. (2015). 5 Characteristics of a committed employee. Diperoleh pada 26 Jun2018daripadahttp://www.webrecruitireland.com/employer.../5-characteristics-of-a-committedemployee.

Williams, M., \& Burden, R. (1997). Psychology for language teachers: A social constructivist approach. Cambridge: Cambridge University Press. 